\title{
Total Synthesis of Clavosolide A via Tandem Allylic Oxidation/Oxa-Conjugate Addition Reaction
}

\author{
Joseph B. Baker ${ }^{\mathrm{a}}$, Hyoungsu Kim*, ${ }^{*}$, Jiyong Hong *,a \\ ${ }^{a}$ Department of Chemistry, Duke University, Durham, North Carolina 27708, United States \\ ${ }^{\mathrm{b}}$ College of Pharmacy, Ajou University, Suwon 443-749, South Korea \\ * Corresponding author. \\ Tel.: +1 919660 1545; fax: +1 9196601605 . \\ E-mail address: jiyong.hong @ duke.edu (J. Hong). \\ Tel.: +82 31219 3448; fax: +82 312193435 . \\ E-mail address: hkimajou@ajou.ac.kr (H. Kim).
}

\begin{abstract}
The tandem allylic oxidation/oxa-conjugate addition reaction promoted by the gemdisubstituent effect in conjunction with the NHC-mediated oxidative esterification was explored for the facile synthesis of clavosolide A.
\end{abstract}

Keywords: clavosolide, total synthesis, natural product, tandem reaction, oxa-conjugate addition, gem-disubstituent effect, tetrahydropyran

(-)-Clavosolide A (1, Figure 1) is a dimeric glycosidic macrolide isolated from the marine sponge Myriastra clavosa collected in the Philippines by Faulkner and co-workers. ${ }^{1}$ Based on extensive spectroscopic studies and molecular modeling, they reported the proposed structure of clavosolide A (2, Figure 1) which includes a $C_{2}$-symmetric 20-membered macrolide, two 2,3-trans-2,6-cis-tetrahydropyprans, two permethylated D-xyloses, and two transcyclopropanes. Unique structural features of $\mathbf{1}$ have attracted considerable interest from the synthetic community. ${ }^{2}$ Willis and co-workers reported the first total synthesis of the proposed structure (2) of the natural product, which led to the revision of the configuration of the trans- 
cyclopropanes. ${ }^{2 a}$ Later, the total synthesis of $\mathbf{1}$ by Lee and co-workers confirmed the structural revision. $^{2 b}$

Figure 1. Proposed and revised structures of clavosolide A (1).

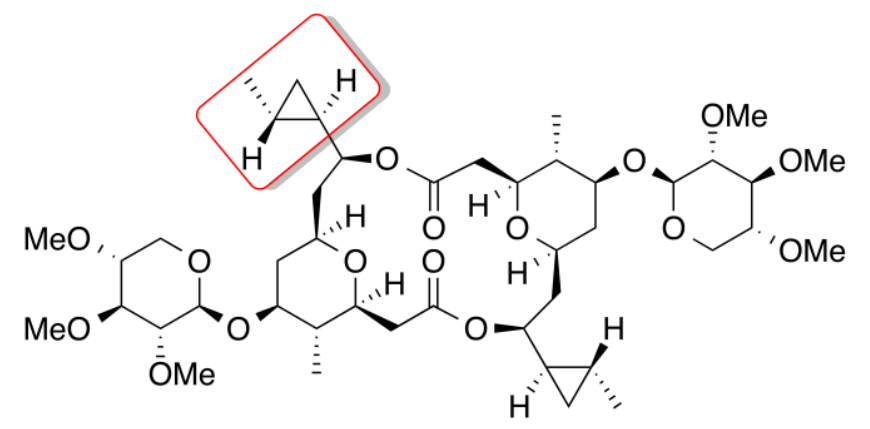

Revised structure of clavosolide A (1)

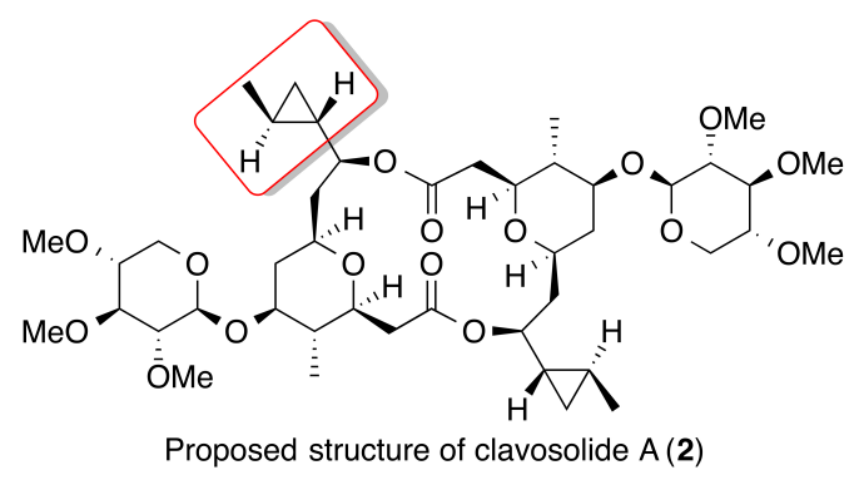

In broad connection with our interest in efficient syntheses of tetrahydropyrancontaining natural products, ${ }^{3}$ herein, we report a facile synthesis of $\mathbf{1}$, enlisting the tandem allylic oxidation/oxa-conjugate addition reaction promoted by the gem-disubstituent effect in conjunction with the NHC-mediated oxidative esterification to stereoselectively construct the 2,3-trans-2,6-cis-tetrahydropyrans embedded in $\mathbf{1}$. 
Scheme 1. Retrosynthetic plan for clavosolide A (1).

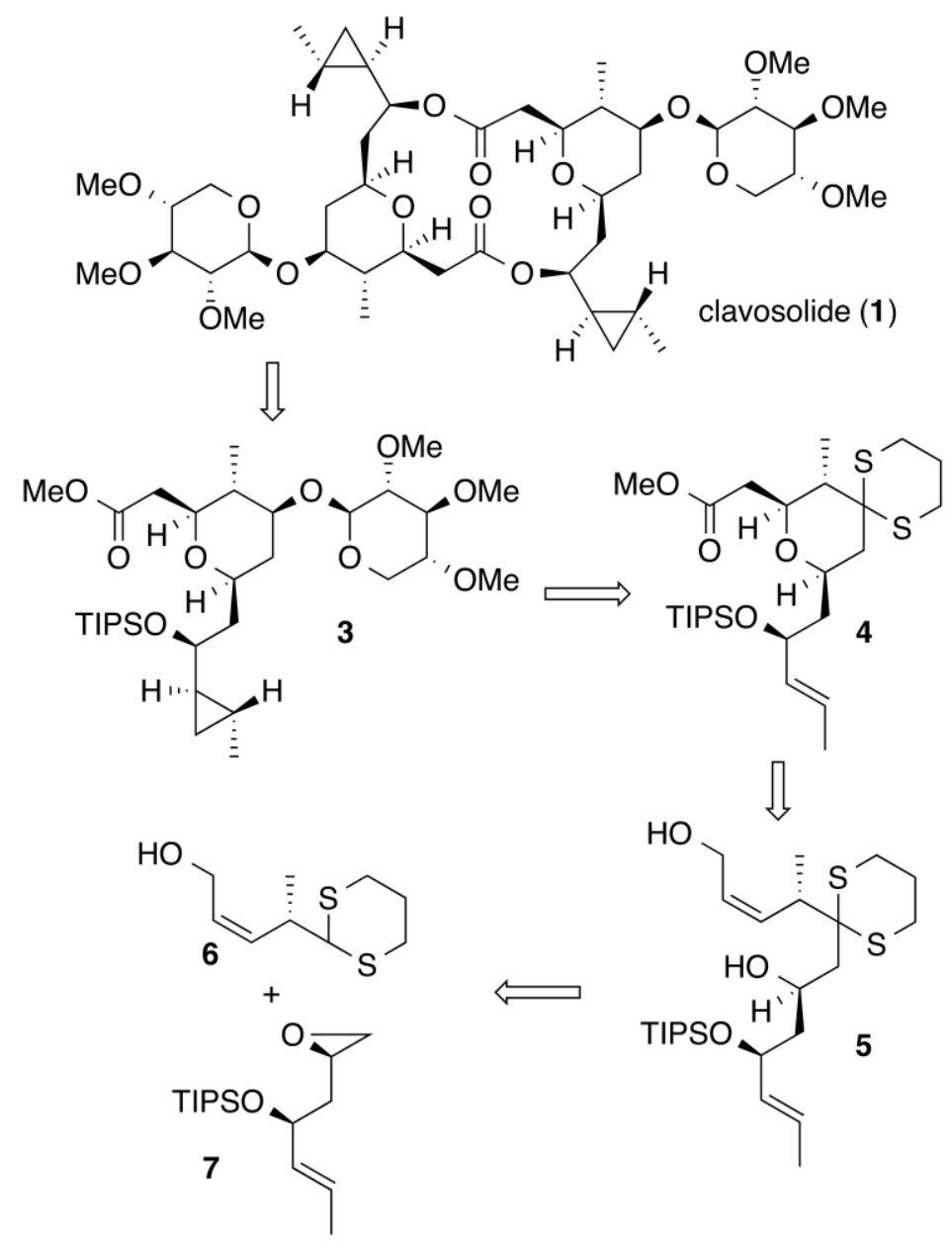

Scheme1 summarizes our approach for the stereoselective synthesis of clavosolide A (1) from the readily available 1,3-dithiane $\mathbf{6}$ and chiral epoxide 7 . The primary goal of our synthetic plan was to explore the tandem allylic oxidation/oxa-conjugate addition reaction for the stereoselective construction of the 2,3-trans-2,6-cis-tetrahydropyran methyl ester $\mathbf{4}$. To that end, we envisioned that a dimerization of monomer $\mathbf{3}$ appendaged with the xylose moiety could complete the synthesis of $\mathbf{1}$. Monomer 3 could be prepared by glycosylation of $\mathbf{4}$ with a permethyl xylose followed by installation of the trans-cyclopropane moiety on 2,3-trans-2,6-cistetrahydropyran methyl ester 4 . The sequence of tandem allylic oxidation/oxa-conjugate addition reaction $^{3}$ and NHC-mediated oxidative esterification ${ }^{3 a, b, 6}$ was anticipated to stereoselectively 
provide the key intermediate 2,3-trans-2,6-cis-tetrahydropyran methyl ester 4.

Scheme 2. Preparation of epoxide 7.

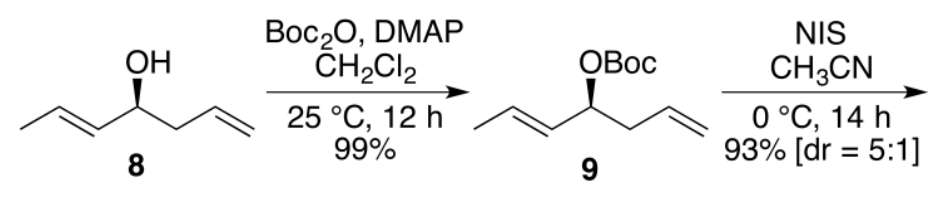<smiles>C/C=C/C1CC(CI)OC(=O)O1</smiles>

10

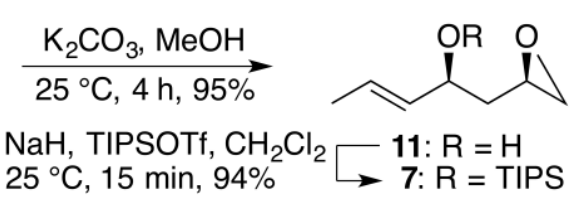

The synthesis of clavosolide (1) started with the preparation of chiral epoxide $\mathbf{7}$ for dithiane coupling reaction. Preparation of $\mathbf{7}$ from the known allylic alcohol $\mathbf{8}^{4}$ was accomplished following the procedures reported by Smith and co-workers (Scheme 2). ${ }^{5}$ Briefly, formation of acyclic tert-butyl carbonate 9 (99\%) followed by iodocyclization of 9 afforded the corresponding cyclic carbonate $\mathbf{1 0}(93 \%, \mathrm{dr}=5: 1)$. Methanolysis of $\mathbf{1 0}$ and the concomitant epoxide formation of the resulting 1,2-iodohydrin gave epoxide $\mathbf{1 1}$ (95\%), which was then protected to afford TIPS ether 7 (94\%).

Scheme 3. Preparation of 2,3-trans-2,6-cis-tetrahydropyran methyl ester 4.
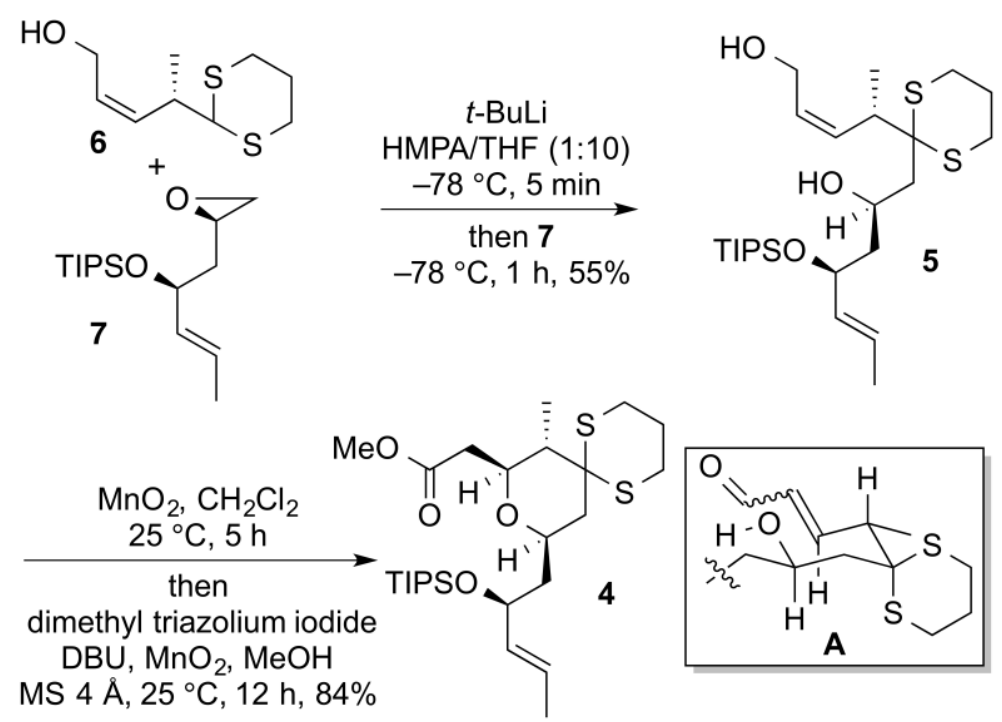
The coupling of the known 1,3-dithiane $\mathbf{6}^{3 \mathrm{c}, \mathrm{f}}$ and chiral epoxide 7 provided diol 5 for the key tandem allylic oxidation/oxa-conjugate addition reaction (Scheme 3). The one-pot allylic oxidation/oxa-conjugate addition/oxidation of $\mathbf{5}\left(\mathrm{MnO}_{2}, \mathrm{CH}_{2} \mathrm{Cl}_{2}, 25{ }^{\circ} \mathrm{C}, \quad 5 \mathrm{~h}\right.$, then dimethyltriazolium iodide, $\left.\mathrm{DBU}, \mathrm{MnO}_{2}, \mathrm{MeOH}, \mathrm{MS} 4 \AA, 25^{\circ} \mathrm{C}, 12 \mathrm{~h}\right)^{3 \mathrm{a}, \mathrm{b}}$ smoothly proceeded to afford the desired 2,3-trans-2,6-cis-tetrahydropyran methyl ester 4 (84\%) as a single diastereomer. $^{7}$ The excellent stereoselectivity observed in the oxa-conjugate addition reaction can be rationalized by involving a highly rigid chair-like transition state conformation (A) induced by the 1,3-dithiane and the equatorially oriented methyl group. It is noteworthy that the sequence of 1,3-dithiane coupling and tandem reaction was highly stereoselective, operationally simple, and robust.

Scheme 4. Completion of total synthesis of clavosolide A (1).

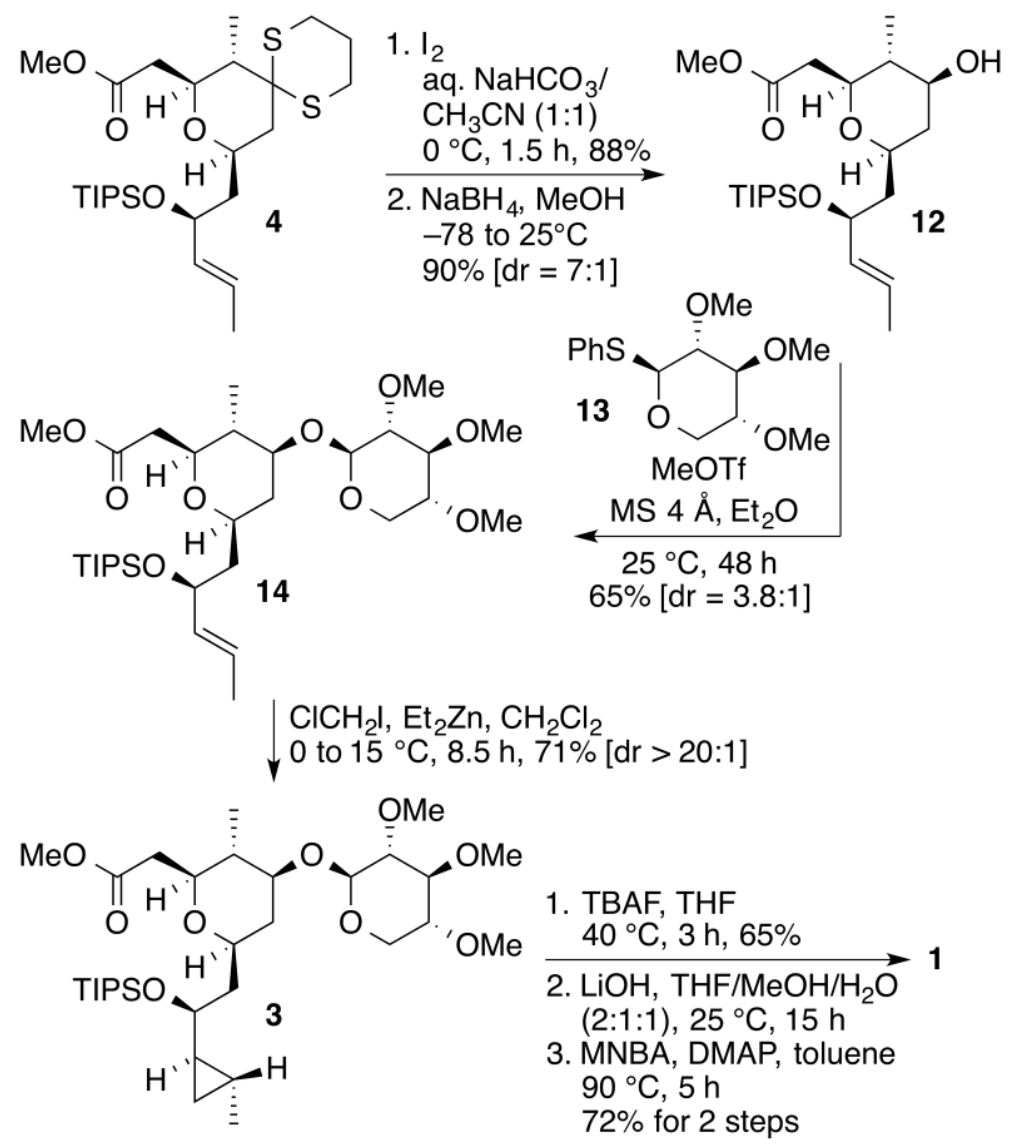


With the key intermediate 2,3-trans-2,6-cis-tetrahydropyran methyl ester 4 in hand, we directed our attention to the final stage of the synthesis. Iodine-mediated dithiane-deprotection of $4(88 \%)$ followed by $\mathrm{NaBH}_{4}$-reduction of the resulting ketone afforded secondary alcohol $\mathbf{1 2}$ in $90 \%$ yield (Scheme 4). Glycosylation of $\mathbf{1 2}$ with phenyl thioglycoside $\mathbf{1 3}^{2 \mathrm{a}}$ in the presence of MeOTf gave the desired $\beta$-anomeric monomer $14(65 \%, \mathrm{dr}=3.8: 1){ }^{8}$ The Simmons-Smith cyclopropanation of $\mathbf{1 4}$ provided cyclopropane $\mathbf{3}(71 \%)$ as a single diastereomer. Finally, TIPSdeprotection (65\%), ester hydrolysis, and dimerization utilizing Shiina's procedure ${ }^{9}$ ( $72 \%$ for two steps) completed the synthesis of clavosolide A (1). The synthetic clavosolide A (1) was identical in all respects to the natural product.

In conclusion, the total synthesis of clavosolide A (1) has been accomplished with overall 3.6\% yield in 13 steps for the longest sequence from the known allylic alcohol 8 . Highlights of the synthesis include the one-pot allylic oxidation/oxa-conjugate addition/oxidation reaction to stereoselectively construct 2,3-trans-2,6-cis-tetrahydropyran methyl ester $\mathbf{4}$ from the readily available 1,3-dithiane $\mathbf{6}$ and chiral epoxide 7. This synthetic approach would be broadly applicable to the synthesis of other clavosolides and their analogues for future biological studies.

\section{Acknowledgment}

We are grateful to Duke University for funding this work, to the North Carolina Biotechnology Center (NCBC; Grant No. 2008-IDG-1010) for funding of the NMR instrumentation, and to the National Science Foundation (NSF) MRI Program (Award ID No. 0923097) for funding mass spectrometry instrumentation. J.B.B. was supported by the NIGMS Pharmacological Sciences Training Grant (NIH GM007105).

\section{References}

(1) Rao, M. R.; Faulkner, D. J. J. Nat. Prod. 2002, 65, 386.

(2) (a) Barry, C. S.; Bushby, N.; Charmant, J. P. H.; Elsworth, J. D.; Harding, J. R.; Willis, C. L. Chem. Commun. 2005, 5097. (b) Son, J. B.; Kim, S. N.; Kim, N. Y.; Lee, D. H. Org. Lett. 2006, 8, 661. (c) Chakraborty, T. K.; Reddy, V. R. Tetrahedron Lett. 2006, 47, 2099. (d) Smith, A. B., 
III; Simov, V. Org. Lett. 2006, 8, 3315. (e) Barry, C. S.; Elsworth, J. D.; Seden, P. T.; Bushby, N.; Harding, J. R.; Alder, R. W.; Willis, C. L. Org. Lett. 2006, 8, 3319. (f) Chakraborty, T. K.; Reddy, V. R.; Chattopadhyay, A. K. Tetrahedron Lett. 2006, 47, 7435. (g) Chakraborty, T. K.; Reddy, V. R.; Gajula, P. K. Tetrahedron 2008, 64, 5162. (h) Carrick, J. D.; Jennings, M. P. Org. Lett. 2009, 11, 769. (i) Son, J. B.; Kim, S. N.; Kim, N. Y.; Hwang, M.-H.; Lee, W.; Lee, D. H. Bull. Korean Chem. Soc. 2010, 31, 653. (j) Peh, G. R.; Floreancig, P. E. Org. Lett. 2012, 14, 5614.

(3) (a) Kim, H.; Park, Y.; Hong, J. Angew. Chem., Int. Ed. 2009, 48, 7577. (b) Kim, H.; Hong, J. Org. Lett. 2010, 12, 2880. (c) Lee, K.; Kim, H.; Hong, J. Org. Lett. 2011, 13, 2722. (d) Park, H.; Kim, H.; Hong, J. Org. Lett. 2011, 13, 3742. (e) Byeon, S. R.; Park, H.; Kim, H.; Hong, J. Org. Lett. 2011, 13, 5816. (f) Lee, K.; Kim, H.; Hong, J. Eur. J. Org. Chem. 2012, 1025 (g) Lee, K.; Kim, H.; Hong, J. Angew. Chem., Int. Ed. 2012, 51, 5735.

(4) Yadav, J. S.; Rao, P. P.; Reddy, M. S.; Rao, N. V.; Prasad, A. R. Tetrahedron Lett. 2007, 48,1469 .

(5) Duan, J. J.-W.; Smith, A. B., III. J. Org. Chem. 1993, 58, 3703

(6) Maki, B. E.; Scheidt, K. A. Org. Lett. 2008, 10, 4331.

(7) Compound 4: To a solution of diol 5 (117 mg, $0.24 \mathrm{mmol})$ in $\mathrm{CH}_{2} \mathrm{Cl}_{2}(4 \mathrm{~mL}, 0.06 \mathrm{M})$ at $25^{\circ} \mathrm{C}$ was added $\mathrm{MnO}_{2}(89 \mathrm{mg}, 1.02 \mathrm{mmol})$. The resulting solution was stirred at $25{ }^{\circ} \mathrm{C}$ for $1 \mathrm{~h}$. Additional equivalents of $\mathrm{MnO}_{2}(89 \mathrm{mg}, 1.02 \mathrm{mmol})$ were added every hour for $4 \mathrm{~h}$. The reaction mixture was then treated with a mixture of dimethyltriazolium iodide $(5 \mathrm{mg}, 0.022 \mathrm{mmol}, 9$ mol\%), DBU (410 $\mu \mathrm{L}, 1 \mathrm{M}$ solution in $\left.\mathrm{CH}_{2} \mathrm{Cl}_{2}\right), \mathrm{MnO}_{2}(89 \mathrm{mg}, 1.02 \mathrm{mmol}), \mathrm{MeOH}(400 \mu \mathrm{L})$, and MS $4 \AA$ (585 mg, $500 \mathrm{wt} \%$ ). The resulting mixture was stirred for $12 \mathrm{~h}$. The crude mixture was then filtered through a small plug of celite and concentrated in vacuo. The crude mixture was purified by column chromatography (silica gel, hexanes/EtOAc, 5/1) to provide 2,3-trans2,6-cis-tetrahydropyran methyl ester 4 (104 mg, $0.20 \mathrm{mmol})$ in $84 \%$ as a clear oil; ${ }^{1} \mathrm{H}$ NMR (500 
$\left.\mathrm{MHz}, \mathrm{CDCl}_{3}\right) \delta 5.56(\mathrm{dddd}, J=15.5,8.5,8.5,8.5 \mathrm{~Hz}, 1 \mathrm{H}), 5.39(\mathrm{ddd}, J=15.0,8.5,1.5 \mathrm{~Hz}, 1 \mathrm{H})$, 4.31 (ddd, $J=8.5,8.5,4.0 \mathrm{~Hz}, 1 \mathrm{H}), 3.89$ (ddd, $J=9.5,9.5,3.0 \mathrm{~Hz}, 1 \mathrm{H}), 3.81$ (dddd, $J=9.5,9.5$, 3.5, $1.5 \mathrm{~Hz}, 1 \mathrm{H}), 3.68$ (s, $3 \mathrm{H}), 3.12$ (ddd, $J=15.0,12.5,3.0 \mathrm{~Hz}, 1 \mathrm{H}), 2.89$ (ddd, $J=15.0,12.5$, $3.0 \mathrm{~Hz}, 1 \mathrm{H}), 2.59-2.68(\mathrm{~m}, 3 \mathrm{H}), 2.54(\mathrm{dd}, J=14.5,3.0 \mathrm{~Hz}, 1 \mathrm{H}), 2.31(\mathrm{dd}, J=14.5,9.5 \mathrm{~Hz}, 1$ H), 2.07-2.10 (m, 1 H), 1.78-1.86 (m, 2 H), $1.73(\mathrm{dd}, J=13.5,10.5 \mathrm{~Hz}, 1 \mathrm{H}), 1.70$ (dd, $J=6.0$, $1.5 \mathrm{~Hz}, 3 \mathrm{H}), 1.64(\mathrm{dd}, J=10.0,7.0 \mathrm{~Hz}, 1 \mathrm{H}), 1.50(\mathrm{ddd}, J=13.0,9.0,3.5 \mathrm{~Hz}, 1 \mathrm{H}), 1.14(\mathrm{~d}, J=$ $7.0 \mathrm{~Hz}, 3 \mathrm{H}), 1.04$ (s, $21 \mathrm{H}) ;{ }^{13} \mathrm{C} \mathrm{NMR}\left(125 \mathrm{MHz}, \mathrm{CDCl}_{3}\right) \delta 172.0,134.2,125.9,73.9,71.0,70.6$, $54.9,51.7,45.7,44.3,43.8,39.7,25.88,25.83,25.2,18.24,18.21,17.8,12.5$.

(8) (a) Lönn, H. J. Carbohydr. Chem. 1987, 6, 301. (b) Watanabe, H.; Nakada, M. J. Am. Chem. Soc. 2008, 130, 1150.

(9) (a) Shiina, I.; Kubota, M.; Oshiumi, H.; Hashizume, M. J. Org. Chem. 2004, 69, 1822. (b) Shiina, I.; Fukui, H.; Sasaki, A. Nat. Protoc. 2007, 2, 2312. 


\section{Graphical Abstract}

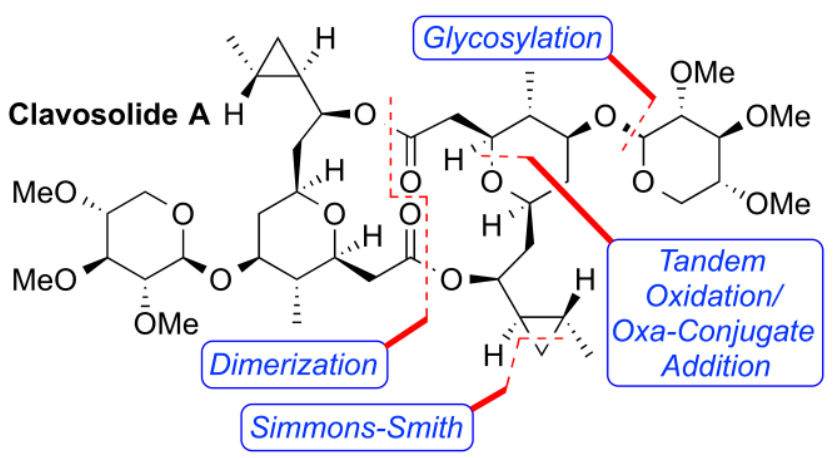

